Journal of Health Promotion and Behavior (2018), 3(3): 192-198

https://doi.org/10.26911/thejhpb.2018.03.03.06

\title{
Application of Health Belief Model on Preventive Behaviors of Patients with Low Back Pain
}

\author{
Septi Ayu Arum Yuspita Sari'1), Dono Indarto' ${ }^{2)}$, Mahendra Wijaya3) \\ 1)Masters Program in Public Health, Universitas Sebelas Maret \\ 2)Department of Physiology, Faculty of Medicine, Universitas Sebelas Maret \\ 3)Faculty of Social and Political Sciences, Universitas Sebelas Maret
}

\begin{abstract}
Background: Low back pain (LBP) has different negative impacts in some people around the world. There are many risk factors of LBP, either biology, psychology, or social economics. A psychological theory (Health Belief Model/HBM) can be applied for preventive behaviors of some human diseases. This study aimed to analyze the application of HBM on preventive behaviors of patients with LBP.

Subjects and Method: This was a case-control study conducted at the medical rehabilitation policlinic, Dr. Moewardi Hospital, Surakarta, from October to November 2018. A sample of 50 LBP patients and 100 non-LBP patients was selected by fixed exposure sampling. The dependent variable was preventive behaviors. The independent variables were perceived severity, susceptibility, benefit, barrier, threat, cues to action, and self-efficacy. Data on LBP was obtained from medical record. The other data were collected by questionnaire and analyzed by path analysis. Results: LBP preventive behaviors were directly and positively associated with perceived threat $(\mathrm{b}=0.46 ; 95 \% \mathrm{CI}=0.24$ to $0.68 ; \mathrm{p}<0.001)$, perceived benefit $(\mathrm{b}=0.29 ; 95 \% \mathrm{CI}=0.18$ to 0.40 ; $\mathrm{p}<0.001)$, and self-efficacy $(\mathrm{b}=0.16 ; 95 \% \mathrm{CI}=0.08$ to $0.23 ; \mathrm{p}<0.001)$. It was indirectly associated with perceived susceptibility, perceived severity, perceived barrier, and cues to action.

Conclusion: LBP preventive behaviors are directly and positively associated with perceived threat, perceived benefit, and self-efficacy. It is indirectly associated with perceived susceptibility, perceived severity, perceived barrier, and cues to action. This study supports the application of HBM to explain LBP preventive behaviors.
\end{abstract}

Keywords: low back pain, Health Belief Model, path analysis

\section{Correspondence:}

Septi Ayu Arum Yuspita Sari. Masters Program in Public Health, Universitas Sebelas Maret. Jl. Ir. Sutami 36A, Surakarta 57126, Central Java. Email:yuspitasario20993@gmail.com.

Mobile: +6282338986991.

\section{BACKGROUND}

In global perspective, most people have different impact of low back pain (LBP). (Henschke et al., 2016). This disorder results in reduction of productivity in some American workers due to frequent leaves from their works (Goode et al., 2012). According to Koley et al (2010), chronic pain is commonly found in LBP patients who lived in Amritsar, Punjab, Indiathat restrict mobility, interferenormal functions of human body andresult in permanent disability. Mostpeople with low income are engaged in physically demanding jobs, which may increase the risk of LBP. Low back pain affects the quality of life (QOL) not only women but also their families (Bansal et al., 2016). However, a few studies have reported the LBP impacts in Indonesian workers.

Risk factors of LBP vary among people around the world. From biological conditions, some studies have indicated that sex, age, marital status and body mass index are related to LBP. Chaman et al. (2015) stated that prevalence of LBP was 
$\mathbf{2 7 . 4 \%}$ in Iranese women who worked as carpet weaver. The higher risk of LBP in those women was due to older age and married status. Another study conducted in Grave in Chianti (rural area) and Bagno a Ripoli(urban area near Florence), Italia reported that prevalence of LBP in elder women was higher than the prevalence of LBP in elder man. The Italian women with menopause who had reduction of bone density have stronger association with LBP (Cecchi, 2006). However, a Japanese study documented that age indirectly correlated with LBP trough sleep quality (Murase et al., (2015).

In addition, education, prior LBP knowledge and physical activity correlate to LBP. From an Australian study, low education level increases 0.65 higher risk of recovery of LBP, compared to high education level (Costa et al., 2009) but there is no study so far investigating the association between education level and preventive behaviors of LBP. Lack of LBP knowledge is not only found in people who have low education level but also in educated people. Based on a study conducted in Amirkabir General Hospital, Iran, the LBP knowledge of some Iranese nurses increases signifycantly after three month education of LBP preventive behaviors, leading to reduction of LBP risk (Sharafkhani et al., 2016).

Some daily activities may also trigger LBP in Indonesian communities. For example, women who perform their house works such as washing clothes manually, lifting up cooking tools and carrying kids with their back have higher risk to suffer LBP. Unfortunately, there is no research study in Indonesia that reports the incidence of LBP in those people. On the other hand, Indian women perform daily works in inner or outer houses. They also do some works like farmer in rice field and livestock as doing by Indonesian men. They have improper position such us bending their back for long time, which increase $60 \%$ risk of LBP compared to Indian women who live in urban areas (Ahdhi et al., 2017).

The second habit is sitting position. Many Indonesian people sit more than 2 hour without stretching during their daily works. They also sit on the chair without back support. In United State, the majority of American peoples work in state or private offices and they spend more time for sitting than walking (Costa et al., 2009). Health Belief Model (HBM) is a psychological theory that is commonly used for prevention of human diseases by emphasizing individual perception. The HBM consists of 4 main constructs (perceived susceptibility, severity, benefits and barrier) and 2 additional constructs (self-efficacy and cues to action) (Orji et al., 2012), which has been used for behavior prevention of osteoarthritis, LBP, skin cancer and accident trauma in children (Coulson et al., 2016; Glanz dan Bishop, 2010). Therefore, the aim of this study was to investigate the application of HBM on preventive behaviors of patients with LBP.

\section{SUBJECTS AND METHOD \\ 1. Study Design \\ This was a case-control study conducted at medical rehabilitation policlinic, Dr. Moe- wardi Hospital, Surakarta, Central Java, Indonesia, from October to November 2018.}

\section{Population and Sample}

The population of this study was all outward patients who visited medical rehabilitation policlinic of the Dr. Moewardi Hospital, Surakarta. A sample of 50 LBP patients and 100 non-LBP patients was selected by fixed exposure sampling.

\section{Study Variables}

The dependent variable was LBP preventive behaviors. The independent variables were 
Journal of Health Promotion and Behavior (2018), 3(3): 192-198

https://doi.org/10.26911/thejhpb.2018.03.03.06

perceived severity, susceptibility, benefit, barrier, and threat, cues to action, and selfefficacy.

\section{Data Analysis}

Sample characteristics were described by univariate analysis. Bivariate analysis used Chi square. Multivariate analysis used path analysis to determine the direct and indirect effects of the relationships between study variables. Path analysis steps included model specification, model identification, model fit, parameter estimate, and model re-specification.

\section{Research Ethics}

The research ethical clearance was obtained from the Research Ethics Committee at Faculty of Medicine, Universitas Sebelas Maret, Surakarta, Central Java, Indonesia, No. 234/UN27.6/KEPK/2018 with protocol

Table 1. Sample characteristics

\begin{tabular}{lcc}
\hline \multicolumn{1}{c}{ Variables } & Case & Control \\
\cline { 2 - 3 } Sex & N (\%) & N(\%) \\
Male & & \\
Female & $12(24)$ & $41(41)$ \\
Age & $38(76)$ & $59(59)$ \\
17-25 years old & & \\
26-35 years old & $1(2)$ & $9(9)$ \\
36-45 years old & $3(6)$ & $6(6)$ \\
46-55 years old & $2(4)$ & $21(21)$ \\
$56-65$ years old & $6(12)$ & $31(31)$ \\
>65 years old & $10(20)$ & $17(17)$ \\
Occupation & $28(56)$ & $16(16)$ \\
Civil Servants & & $5(5)$ \\
Farmers & $13(26)$ & $10(10)$ \\
Entrepreneurs & $2(4)$ & $13(13)$ \\
Housewife & $3(6)$ & $68(68)$ \\
Retired & $29(58)$ & $4(4)$ \\
Education & $3(6)$ & $4(4)$ \\
Primary school & & $37(37)$ \\
Junior high school & $5(10)$ & $51(51)$ \\
Senior high school & $34(68)$ & $8(8)$ \\
Bachelor & $8(16)$ & \\
\hline
\end{tabular}

\section{Bivariate Analysis}

The Pearson product moment correlation was used to know individual correlation between HBM constructs and preventive
ID 01/18/08/223. Research ethics included issues such as informed consent, anonymity, confidentiality, and ethical clearance.

\section{RESULTS}

\section{Sample characteristics}

Table 1 showed the sample characteristics. Table q showed that. Both case and control groups had similar characteristics in sex and occupation. More than 50\% study subjects of case and control group were female with housewife occupation. More study subjects in the case group were older than study subjects in the control group. Lower education background was observed in study subjects of the case group, compared study subjects of the control group. behaviors of LBP. Table 2 showed the results of bivariate analysis. Table 2 showed that perceived severity $(\mathrm{r}=0.19 ; \mathrm{p}=0.019)$, perceived susceptibility $(\mathrm{r}=0.39 ; \mathrm{p}<0.001)$, 
perceived benefit $(\mathrm{r}=0.35 ; \mathrm{p}<0.001)$, perceived threat $(\mathrm{r}=0.44 ; \mathrm{p}<0.001)$, cues to action ( $\mathrm{r}=0.32 ; \mathrm{p}<0.001)$, and self-efficacy $(\mathrm{r}=0.23 ; \mathrm{p}<0.001)$ increased the preventive behavior of LBP. Perceived barriers ( $\mathrm{r}=$ -0.31; $\mathrm{p}<0.001$ ) decreased the preventive behavior of LBP.

Tabel 2. The results of Pearson product moment correlation

\begin{tabular}{lcc}
\hline $\begin{array}{c}\text { Independent } \\
\text { Variables }\end{array}$ & $\mathbf{r}$ & $\mathbf{p}$ \\
\hline Perceived severity & 0.19 & 0.019 \\
Perceived susceptibility & 0.39 & $<0.001$ \\
Perceived benefits & 0.35 & $<0.001$ \\
Perceived barriers & -0.31 & $<0.001$ \\
Perceived threat & 0.44 & $<0.001$ \\
Cues to action & 0.32 & $<0.001$ \\
Self-efficacy & 0.23 & $<0.001$ \\
\hline
\end{tabular}

\section{Results of Path Analysis}

Figure 1 depicted the results of path analysis model. Figure 1 showed that te number of endogenous variables were 8 and the number exogenous variables were 2. Degree of freedom (df) was 4 , the Root Mean Square Error of Approximation (RMSEA) value was <0.001.

Akaike Information Criterion (AIC) was 5544.4 and Bayesian Information Criterion (BIC) was 5661.81 with probability level $(\mathrm{p})=0.184$.

Table 3 showed LBP preventive behavior was directly increased with perceived threat $(b=0.46 ; 95 \% \mathrm{CI}=0.24$ to 0.68 ; $\mathrm{p}<0.001)$, perceived benefit $(\mathrm{b}=0.29 ; 95 \%$ $\mathrm{CI}=0.18$ to $0.40 ; \mathrm{p}<0.001)$ and self-efficacy $(b=0.16 ; 95 \% \mathrm{CI}=0.08$ to $0.23 ; \mathrm{p}$ $<0.001)$.

LBP preventive behavior was indirectly associated with perceived susceptibility, perceived severity, perceived threat, and cues to action.

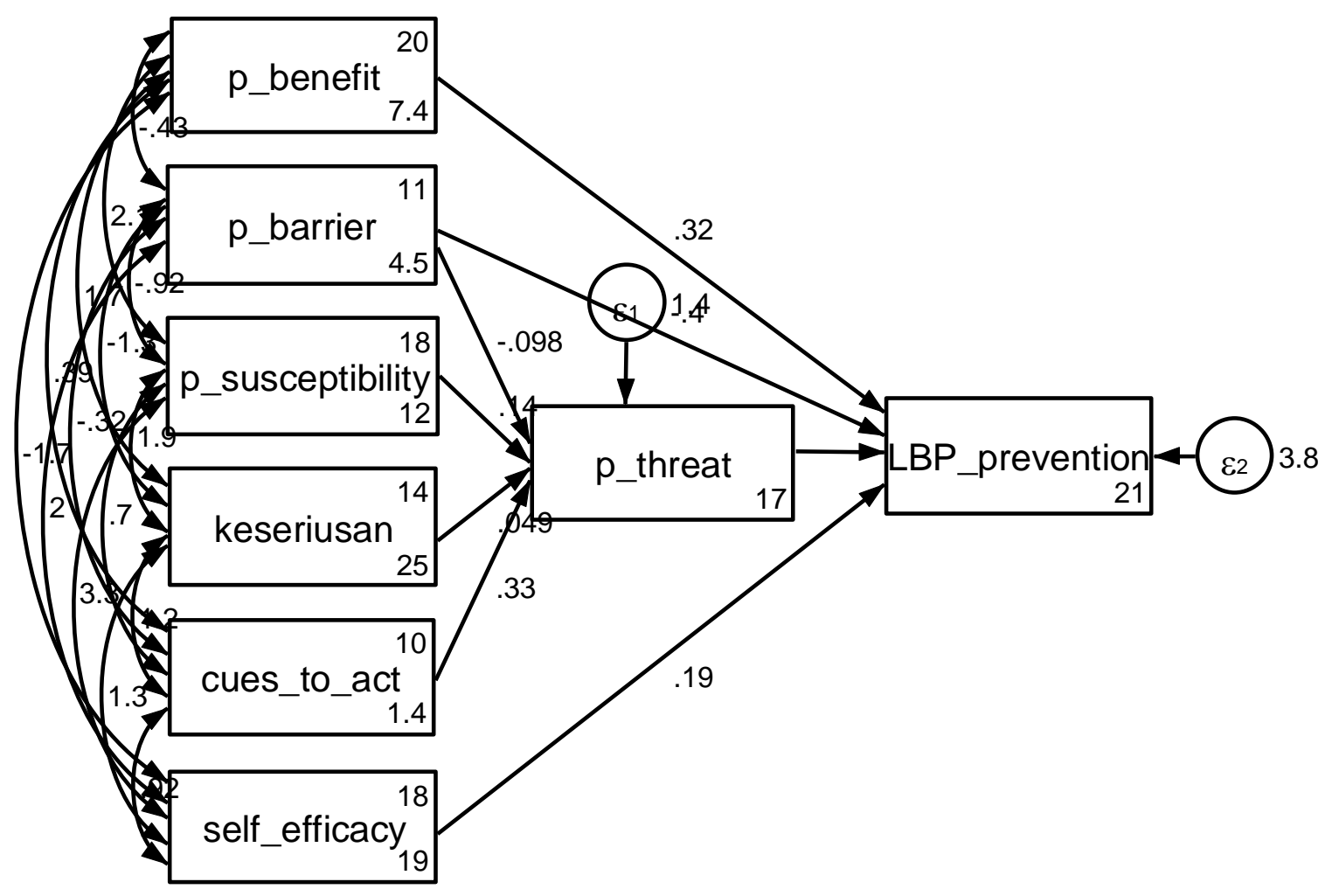

Figure 1. The path analysis models 
Journal of Health Promotion and Behavior (2018), 3(3): 192-198

https://doi.org/10.26911/thejhpb.2018.03.03.06

Table 3. Results of path analysis

\begin{tabular}{|c|c|c|c|c|c|c|c|}
\hline \multirow{2}{*}{$\begin{array}{l}\text { Dependent } \\
\text { Variables }\end{array}$} & & \multirow{2}{*}{$\begin{array}{l}\text { Independent } \\
\text { Variables }\end{array}$} & \multirow[b]{2}{*}{$\mathbf{b}$} & \multicolumn{2}{|c|}{ CI 95\% } & \multirow[b]{2}{*}{$\mathbf{p}$} & \multirow[b]{2}{*}{$\boldsymbol{\beta}$} \\
\hline & & & & $\begin{array}{c}\text { Lower } \\
\text { limit }\end{array}$ & $\begin{array}{l}\text { Upper } \\
\text { limit }\end{array}$ & & \\
\hline \multirow{5}{*}{$\begin{array}{l}\text { Direct Influence } \\
\text { Preventive behaviors }\end{array}$} & $\leftarrow$ & & & & & & \\
\hline & $\leftarrow$ & Perceived threat & 0.46 & 0.24 & 0.68 & $<0.001$ & 0.28 \\
\hline & $\leftarrow$ & Perceived barriers & -0.31 & -0.45 & -0.16 & $<0.001$ & -0.28 \\
\hline & $\leftarrow$ & Perceived benefits & 0.29 & 0.18 & 0.40 & $<0.001$ & 0.33 \\
\hline & $\leftarrow$ & Self-Efficacy & 0.16 & 0.08 & 0.23 & $<0.001$ & 0.29 \\
\hline \multicolumn{8}{|l|}{ Indirect Influence } \\
\hline \multirow[t]{4}{*}{ Perceived threat } & $\leftarrow$ & $\begin{array}{l}\text { Perceived } \\
\text { susceptibility }\end{array}$ & 0.14 & 0.08 & 0.19 & $<0.001$ & 0.34 \\
\hline & $\leftarrow$ & Perceived severity & 0.05 & 0.01 & 0.09 & 0.014 & 0.17 \\
\hline & $\leftarrow$ & Cues to action & 0.33 & 0.17 & 0.49 & $<0.001$ & 0.28 \\
\hline & $\leftarrow$ & Perceived barriers & -0.01 & -0.19 & -0.01 & 0.033 & -0.15 \\
\hline \multicolumn{8}{|c|}{$\begin{array}{l}\mathrm{N} \text { observation }=150 \\
\text { Log Likelihood }=-2726.2 \\
\mathrm{~b}=\text { Unstandarized path coefficients } \\
\beta=\text { Standarized path coefficients }\end{array}$} \\
\hline
\end{tabular}

\section{DISCUSSION}

$\overline{\text { An application of HBM on preventive beha- }}$ viors in patients with LBP was firstly conducted at the Surakarta city, Central Java. There are 2 HBM constructs that greatly influence LBP preventive behavior, included perceived benefit and susceptibility. Meanwhile perceived barrier negatively correlates with LBP preventive behaviors through direct and indirect actions. Overall these results suggest that the HBM theory is suitable for prevention of LBP.

The perceived benefit has a stronger positive correlation than perceived threat and self-efficacy towards LBP preventive behavior because the perceived benefit is one important of HBM constructs beside perceived susceptibility, severity and barrier. While the presence of perceived threat is an indirect action, which is influenced by perceived susceptibility and severity. In the same thing, self-efficacy is not the main constructs of HBM, which is influenced by perceived benefit and barrier. In addition, our findings show that per ceived threat and self-efficacy have the same influence to preventive behaviors of LBP.

In the HBM theory, individual tends to do preventive behaviors if his/ her activities have more benefit than threat toward risk reduction of a certain disease like LBP (Chee et al., 2014; Jeihooni et al., 2015). Our study is in line to Cao et al (2014) study in terms of perceived benefit. The Cao study stated that the HBM could be applied for prevention of trauma in Senior High School students and the perceived benefit is the strongest influence among other HBM constructs on preventive behaviors of trauma $(b=0.87, p<0.001)$.

In addition to perceived benefit, the strongest indirect correlation with preventive behaviors of LBP is perceived susceptibility. According to Shaw (2016), people will have high motivation to behave healthy if their perceived susceptibility is negative to certain disease. The Shaw statement is supported by Cao et al. (2014) study that higher perceived susceptibility has stronger behaviors in terms of risk reduction. Result of our study is in accordance to a rando- 
mized control trial study conducted by Sharafkhani et al. (2016). They reported that increased perceived susceptibility in nurses who worked in Amirkabir Hospital, Iran after getting 3 month education, which resulted in increase of LBP preventive behaviors.

The two different correlations of perceived barrier on LBP preventive behaviors are probably mediated by perceived threat. However, the influence of direct correlation on LBP preventive behaviors is stronger than indirect correlation. Our study indicated that high perceived barrier directly decreased preventive behaviors of LBP. For indirect correlation, it can be explained that sometime someone ignores his/her threat when he/she feels not to be susceptible to certain disease or disorder (Orji et al., 2012). Therefore, ignored threats will influence preventive behavior of LBP, which is not as high as the direct correlation. Based on Orji study, individual who has stronger perceived threat of musculoskeletal pain has higher motivation to avoid it.

In contrast to two earlier studies, finding data of Cao et al. (2014) using the randomized control trial study indicated that there is no significant difference between control and treatment groups in senior high school students that received a health education program in terms of perceived barrier on health behaviors.

In conclusion, perceived benefit and susceptibility greatly correlate with LBP preventive behaviors in positive direction. Our results provide valuable information for the department of medical rehabilitation in the Dr. Moewardi Hospital Surakarta in order to improve individually LBP preventive behaviors through HBM implementation.

\section{REFERENCES}

Ahdhi GS, Subramanian R, Saya GK, Yamuna TV (2017). Prevalence of Low Back Pain and its Relation to Quality of Life and Disability among Women in Rural Area of Puducherry, India. Indian Journal of Pain, 30(2).DOI: 10.4103/0970-5333.186467.

Bansal D, Gudala K, Lavudiya S, Ghai B, Arora P (2016). Translation, Adaptation, and validation of hindi version of the pain catastrophizing scale in patients with chronic low back painfor use in India. Pain Medicine, 0: 1-11. doi: $10.1093 / \mathrm{pm} / \mathrm{pnv103}$.

Biglarian A, Seifi B, Bakhshi E, Mohammad K, Rahgozar M, Karimlou M, Serahati $S$ (2012). Low Back pain prevalence and associated factors in iranian population: Findings from the National Health Survey. Pain Research and Treatment.doi:10.1155/2012/65306o.

Chaman R, Aliyari R, Sadeghian F, Shoaa JV, Masoudi M, Zahedi S, Bakhshi MA(2015). Psychosocial Factors and musculoskeletal pain among rural Hand-woven Carpet Weavers in Iran. Safety and Health at Work, 6: 120127.

Chee YJ, Chan HH, Tan NC (2014). Understanding patients' perspective of statin therapy: Can We design a better approach to the management of dyslipidaemia? A Literature Review. Singapore Medical Journal, 55(8): 416-421.

Corrin T, Papadopoulos A (2017). Understanding the Attitudes and perceptions of vegetarian and plant-based diets to shape future health promotion programs. Appetite, 109: 40-47.

Costa LDM, Maher CG, McAuley JH, Hancock MJ, Herbert RD, Refshauge KM, Henschke N (2009). Prognosis for patients with chronic low back 
pain: Inception Cohort Study. BMJ, 339:b3829. doi:10.1136/bmj.b3829.

Coulson NS, Ferguson MA, Henshaw H, Heffernan E (2016). Applying theories of health behaviour and change to hearing health research: Time for a new approach. International Journal of Audiology, 55(3): S99-S104. doi: 10.3109/14992027.2016.116185.

Dinakar P, Stillman AM (2016). Pathogenesis of Pain. Seminars in Pediatric Neurology, 23(3): 201-208.

Glanz K, Bishop DB (2010). The role of behavioral science theory in development and implementation of public health interventions. Annual Review of Public Health, 31: 399-418.

Henschke N, Lorenz E, Pokora R, Michaleff ZA, Quartey JNA, Oliveira VC (2016). Understanding cultural influences on back pain and back pain research. Best Practice \& Research: Clinical Rheumatology, 30(6): 1037-1049.

Koley S, Kaur J, Sandhu JS (2010). Biological risk indicators for nonspecific low back pain in young adults of Amritsar, Punjab, India. J Life Sci, 2:43-8.

Murase K, Tabara Y, Ito H, Kobayashi M, Takahashi Y, Setoh K et al. (2015) Knee pain and low back pain additively disturb sleep in the general population: A Cross-Sectional Analysis of the Nagahama Study. PLoS ONE, 10(10): e0140058.

Orji R, Vassileva J, Mandryk R (2012). Towards an effective health interventions design: An Extension of the Health Belief Model. Journal of Public Health Informatics, 4(3):9.

Padchasuwan N, Kaewpitoon SJ, Rujirakul R, Wakkuwattapong P, Norkaew J, Kujapun J, Ponphimai S, Chavenkun W, Kompor P, Kaewpitoon N (2016). Modifying health behavior for liver fluke and cholangiocarcinoma prevention with the health belief model and social support theory. Asian Pacific Journal of Cancer Prevention, 17(8): 3721-3725.

Patton DE, Hughes CM, Cadogan CA, Ryan CA(2017). Theory-based interventions to improve medication adherence in older adults prescribed polypharmacy: A Systematic Review. Drugs Aging, 34(2): 97-113.

Sharafkhani N, Khorsandi M, Shamsi M, Ranjbaran M (2016). The effect of an educational intervention program on the adoption of low back pain preventive behaviors in nurses: An Application of the Health Belief Model. Global Spine Journal, 6(1): 29-34.

Toraman AU, Ardahan M, Balyaci OE (2014). The effect of the body mechanic behaviors on the low back pain. Nurs Pract Today, 1(2): 107-115. 